\title{
UNA CIGÜEÑA EN UNA HIGUERA, UN POTRO EN UN TEJADO, EL ESPEJO DE Didio JUliano Y la MÁSCARA dE HELIOGÁBAlo. BIENVENIDOS AL MUNDO RELIGIOSO DE LOS SIGLOS II Y III D.C. ... SEgún la Historia Augusta \\ A STORK ON A FIG TREe, A COLT ON A Roof, THE MirRor of DidiUs IULIANUS AND THE MASK OF ElAgABALUS. WELCOME TO THE RELIGIOUS WORLD OF THE 2ND AND 3RD CENTURIES A.D. ... acCording to the Historia Augusta
}

JUAN RAMÓN BALLESTERos SÁNCHEZ Universidad Pablo de Olavide, Sevilla JRBALSAN@UPO.ES

\section{RESUMEN}

El capítulo estudia varios textos con alusiones religiosas de la Historia Augusta desde una doble perspectiva. Por un lado, se describen las alusiones satíricas presentes en estos pasajes. Por otro, se reconstruye la crítica política que contienen estos mismos fragmentos. El objetivo último del trabajo es proponer una lectura coherente para el conjunto de la Historia Augusta. Se analizan varios fragmentos de la Vita Marci $(13,6)$, la Vita Pertinaci (1, 2-3 y 14,1-3), la Vita Didii Iuliani (7, 9-11), la Vita Pescennii Nigri (6, 5-8), la Vita Heliogabali (5, 4-5; 6, 4-5 y

\section{Abstract}

The chapter studies several texts of religious content from the Historia Augusta using a double point of view. On the one hand, are described the satirical allusions present in these passages. On the other, the political criticism contained in these fragments is reconstructed. The ultimate goal of this text is to propose a coherent reading for the whole of the Historia Augusta. Several fragments of the Vita Marci $(13,6)$, the Vita Pertinaci (1, 2-3 y 14,1-3), the Vita Didii Iuliani (7, 9-11), the Vita Pescennii Nigri (6, 5-8), the Vita Heliogabali (5, 4-5; 
$28,2)$ y la Vita Alexandri Severi $(49,6)$ para los que el autor proporciona traducciones originales. La lectura de estos textos permite definir el registro historiográfico y la personalidad crítica del esquivo y pícaro autor de la colección de biografías imperiales de los siglos II y III d.C.
$6,4-5$ y 28,2$)$ and the Vita Alexandri Severi $(49,6)$ are analyzed throughout the text. The autor provides original translations of all of them. The reading of this corpus allows to define the historiographic record and the critical personality of the elusive and naughty author of the fundamental collection of imperial biographies from the II and III century AD.

\section{Palabras Clave}

Historia Augusta, sátira política, religión romana

\section{KEYWORDS}

Historia Augusta, political satire, Roman religión 
"Cuando Alejandro Magno hendió el nudo gordiano, se condujo como un verdadero aguafiestas"

Huizinga, J. (1968). Homo ludens (p. 257), Buenos Aires:

Emecé Editores

La Historia Augusta es una obra irritante y provocativa. Los juegos alusivos por medio de los cuales su autor la compuso hacen que las lecturas literales de las biografías imperiales que se reúnen en esta extraña colección resulten incompletas e insatisfactorias. Estos mecanismos alusivos constituyen, en efecto, un desafío para el crítico que aspira a desentrañar sus secretos. Buena parte de estos secretos han permanecido inaccesibles por dos razones. Por un lado, sólo muy recientemente hemos sido conscientes de la naturaleza esencialmente satírica del texto en su conjunto. ${ }^{1}$ Por

1. Ronald Syme subrayó el sentido del humor del "genial impostor" que compuso la Historia Augusta: "a humorist of no mean order" (Syme, 1971, pp. 261-262). Shawn Daniels (Daniels, 2013) ofrece una interpretación sistemática de la Historia Augusta en tanto que sátira. Desde posiciones que tratan de encontrar en las ficciones de la Historia Augusta una motivación exclusivamente religiosa - oposición al cristianismo en un contexto histórico marcado por la polémica religiosa - también se ha defendido el carácter caricaturesco de la obra, cf. Ratti, 2014, 430: "caricature et demie". La bibliografía sobre la risa y lo cómico en el pensamiento y la literatura antigua es extensísima. Me atrevo a citar aquí a Gil Fernández, 1997 y a Beard, 2014. Algunos trabajos específicos sobre la risa, los mecanismos irónicos y el sentido del humor en la Historia Augusta son: Carlozzo, 1978 ("troviamo une discrete messe di facezie", 59), Cascón, 1996 (clasifica los pasajes cómicos de la Historia Augusta en 3 categorías: chistes, descripciones provocadoras de risa y comentarios humorísticos del autor) y Reekmans, 1997 y 2002 (analiza fragmentos humorísticos de la Historia Augusta a la luz de las teorías retóricas de Cicerón y Quintiliano sobre el humor). 
otro lado, no siempre hemos sido capaces de reconstruir el metatexto de buena parte de sus argumentos humorísticos.

Al margen de precisiones más o menos polémicas, existe cierto consenso por parte de la investigación para aceptar que las biografías de la Historia Augusta se escribieron a finales del s. IV o principios del $\mathrm{s}$. V, en época teodosiana o poco después. $^{2} \mathrm{Si}$ obviamos ciertos matices, también es posible reconocer un perfil relativamente preciso para el autor que se esconde detrás de los 6 pseudónimos a los que él mismo atribuyó la obra. ${ }^{3}$ Quizás la gran incógnita pendiente de resolver a propósito de la Historia Augusta sea la del mensaje que se encierra detrás de toda la estructura literaria y erudita con la que se confeccionó semejante engendro historiográfico. Sólo la interpretación del método empleado en la redacción de las biografías puede llevarnos a discernir las intenciones de una obra aparentemente inconsistente y errática, y permitirnos, por fin, atribuir un significado global a los contenidos de la colección.

El autor de la Historia Augusta manejó un importante arsenal erudito para armar su versión de las biografías imperiales de los siglos II y III d.C. Este exuberante bagaje ha llevado a varias generaciones de estudiosos a priorizar en el análisis de la obra el descubrimiento y la exégesis de las fuentes empleadas. ${ }^{4}$ En este sentido, las noticias relativas al mundo religioso del período que se retrata han atraído particularmente la atención de la investigación sobre la Historia Augusta. ${ }^{5}$ Para entender esas noticias, desde antiguo se ha planteado como prioritaria la necesidad de analizar las tendencias religiosas del autor y la posición del mismo en una eventual polémica religiosa entre paganismo y cristianismo. ${ }^{6}$ Este método no ha resuelto de modo convincente los desafíos de la colección. ${ }^{7}$ Para dotar de sentido a la obra y usar la información que proporciona se hace preciso, pues, reconstruir los códigos

2. Desde la obra de Syme viene aceptándose la fecha de 395 d.C. La defensa más reciente de esta datación es la que ha realizado Stéphane Ratti (cf. Ratti, 2014, p. 425, data la obra entre 392 y 394, y, en general, Ratti, 2016). Alan Cameron (Cameron, 2011, p. 772) propuso fechar la obra entre 361 y 386 d.C. Sobre los debates generados por este asunto, en general, Chastagnol, 1994, pp. ix-xxxiv.

3. El perfil de un profesor habituado a "the frivolous atmosphere of the schools" (Adams, 1982, p. 164), que posee el gusto por el chiste fácil (ibid. pp. 43-44: "The autor of the HA had a taste for risqué usages which he had found in earlier comic writings (or in the current language of risqué jokes)") y los hábitos del escoliasta (Syme, 1968, p. 127; "a scholar devoted to the techniques of research", ibid.183). Al margen de esta definición queda la propuesta de identificar al autor de la Historia Augusta con Nicómaco Flaviano senior, un alto dignatario imperial, que ha realizado Stéphane Ratti en varias publicaciones.

4. He analizado las consecuencias de este desmenuzamiento de la obra en Ballesteros, 2018.

5. En la moderna bibliografía, esta perspectiva puede rastrearse, al menos, desde Geffcken, 1920, pp. 279-295.

6. Véase Chastagnol, 1994, pp. cxxxii-cl ("L'atmosphère religieuse").

7. El ataque más sólido a esta perspectiva procede de Cameron, 2011, pp. 743-782 (y passim). 
del proyecto en su conjunto al margen de una perspectiva exclusivamente confesional. Para ello es necesario concebir un contexto más amplio para la Historia Augusta, extender el mensaje de la obra más allá del conflicto religioso, la propaganda confesional o el panfleto de partido.

De hecho, comprender la permanente falta de coherencia del relato constituye, por así decirlo, el nudo gordiano de la Historia Augusta. Si no para cortarlo, al menos para desenmarañar este nudo en la medida de lo posible resulta, a mi juicio, primordial asumir las dos ideas a las que aludíamos al inicio de este trabajo. Por un lado, la Historia Augusta es una sátira, un texto que aspira a mover a risa. Por otro, para entender esta sátira es necesario reconstruir el metatexto al que esta sátira alude. Este metatexto, el conjunto de contextos, textos y referentes objeto de sátira, no es único. Está implícito de modo natural en cada pasaje de la obra. Recuperar los metatextos parodiados haría que la sátira nos resultara, por fin, enteramente inteligible. En este trabajo se ofrecen varias propuestas para reconstruir este horizonte perdido y comprender la reelaboración que del mismo se opera en la Historia Augusta.

Al ritmo de una rutina en sí misma cómica, múltiples noticias sobre adivinación, magia y astrología recorren la Historia Augusta. Se recopilan presagios, se mencionan horóscopos, se describen supersticiones. Sorprendentes procedimientos mágicos conviven con oráculos, sueños premonitorios, prodigios y, también, con antiguas tradiciones religiosas romanas. ${ }^{8}$ Toda esta información constituye el mundo religioso que recrea la Historia Augusta. Para el historiador es una fuente inagotable de información que merece ser estudiada. También requiere de un método específico para poder serlo.

Me propongo presentar con varios ejemplos cómo la Historia Augusta sometió al universo religioso de los s. II y III d.C. a un proceso de reformulación cómica. Para hacerlo parto de la premisa de que la intención del autor de la Historia Augusta fue básicamente paródica. Al reconocer este hecho, cualquier otro significado de la obra puede parecer secundario. No obstante, creo que es posible aceptar que construir una sátira a partir de las biografías imperiales constituye una declaración de intenciones indirectamente política. Las formas esencialmente alusivas, intelectuales y metalingüísticas de la ironía que encierra el tratamiento que la obra realiza de diversos comportamientos religiosos parecen limitar su lectura como discurso historiográfico

8. Cf. Birley, 1991, pp. 29-51, que ha reunido y catalogado los pasajes relevantes de la Historia Augusta con referencias religiosas (sacrificios, divinidades, divinización de los emperadores, cultos orientales, cristianismo...). Previamente, Syme, 1983, pp. 80-97 - un trabajo originalmente publicado en los BHAC 1972/4 (1976) - recorre las noticias sobre astrología presentes en la colección. 
y político. Sin embargo, en el contexto de definitiva consolidación de la autocracia teocrática en el que se confeccionó la Historia Augusta, el reconocimiento de que la risa que promueve este trabajo puede ser un medio de salvación individual, no hace de la Historia Augusta un texto inofensivo en el marco de los grandes problemas colectivos, políticos y religiosos, de su tiempo. Esta puede ser la aportación de la colección al discurso historiográfico al que de un modo explícito pertenece. ${ }^{9}$ Desde este punto de vista, la de la Historia Augusta no sólo fue una de esas épocas que "prefirió contentarse con la palabra y lo formal", ${ }^{10}$ sino que fue una época en la que la ironía siguió siendo uno de los instrumentos más incisivos de la crítica política.

\section{UNA CIGÜEÑA EN UNA HIGUERA: RELIGIÓN, HUMOR Y CRÍTICA EN LA Historia Augusta}

El autor de la Historia Augusta fue, sin lugar a dudas, un maestro en la gestión del despiste. A este imitador de estilos ajenos, más que la de la compilación sistemática y significativa, hay que reconocerle la destreza de la lectura iconoclasta y la del reciclaje de motivos, temas y textos: los pilares de su método creativo. ${ }^{11}$ También fue suya la habilidad de disimular sus intenciones y ocultar referentes. Semejante virtud también ha sido señalada para otros autores clásicos como Tácito. ${ }^{12}$ En el caso del esquivo, tardío y polígrafo autor de las biografías de la Historia Augusta, no obstante, esta habilidad no sólo se empleó para ocultar, bajo una ambigua apariencia retórica, la cruda realidad política del Imperio. La Historia Augusta es una propuesta de disolución de las propias fronteras de dos géneros literarios tradicionales con cuyos recursos fue fabricada: la sátira y la biografía histórica. ${ }^{13}$ Ambos fueron voluntariamente confundidos en la obra. Este procedimiento provocó el efecto inmediato de que la propia labor literaria de quien escribía quedara sometida a la mediación irónica y la consecuencia,

9. No comparto la definición de "historiografía decadente" en la que se englobado la Historia Augusta (por ejemplo, en la introducción de Binaghi Fasce, 1998).

10. La cita procede de Huizinga, 1968, p. 230.

11. Son las cualidades del autor de novela histórica. De hecho, así lo ha calificado uno de los grandes especialistas en la colección, cf. Paschoud, 2014, p. 409: "maître du roman historique".

12. O'Gorman, 2000, p. 3: "Historical understanding in Tacitus' writing, therefore, resides in the continual interplay of these sometimes incompatible features, false appearance and hidden truth."

13. Plinio el joven (Ep. V 8, 11) no quiso combinar dos registros literarios (en su caso la elocuencia política y la historia) por miedo a la confusión que la mezcla pudiera generar en su propio trabajo (non adducor ut duo dissimilia et hoc ipso diversa, quo maxima, confundam misceamque, ne tanta quasi colluvione turbatus ibi faciam quod hic debeo). El autor de la Historia Augusta, en cambio, sí se entregó sin miedo a semejante experimento. 
posiblemente involuntaria, de desorientar a varias generaciones de lectores sobre el sentido de lo que estaba escrito en la Historia Augusta. ${ }^{14}$ Perdida la identidad del autor y en medio del equívoco sentido del proyecto, desaparecieron las claves desde las que era posible entender el tono del singular y travieso historiador que se esconde detrás de la Historia Augusta. Su obra devino el libro que formalmente parecía ser: una colección de biografías imperiales cargada de incoherencias. ${ }^{15}$

Una lectura atenta de la Historia Augusta demuestra que con esta acumulación de incoherencias la obra aspira a no tomarse nada en serio. Uno de los objetivos de este trabajo es demostrar hasta qué punto lo logró. Los aspectos religiosos de las biografías que la integran constituyen un elemento más del programa humorístico que vertebra la colección. Mediante la inclusión de aspectos e instituciones cultuales y religiosas dentro de su plan satírico, la Historia Augusta cuestiona también alguno de los valores heredados de la tradición. Tomemos como ejemplo una anécdota que se cita en la biografía de Marco Aurelio para ilustrar la clemencia del emperador:

Hubo tanta clemencia en su tiempo que ordenó que los gastos de los funerales del vulgo se pagaran con cargo al dinero público y perdonó a cierto embustero timador que le llevaron ante sí y confesó la siguiente fechoría. Con el deseo de encontrar una ocasión para saquear la ciudad y con la ayuda de varios socios, desde una higuera bravía decía a voz en grito a los viandantes del campo de Marte que llovería fuego y que sería el fin del mundo si se convertía en cigüeña cuando él mismo se cayera de la higuera. Trascurrido un tiempo preestablecido se dejó caer y soltó una cigüeña que llevaba escondida en su ropa (HA, Marc. 13, 6). ${ }^{16}$

14. La Historia Augusta ha sido considerada desde el Humanismo como una obra seria. Justo Lipsio, por ejemplo, subrayaba su historica fides. Estudié la relación que Lipsio mantuvo con la historiografía romana en los Admiranda (1598) en Ballesteros, 2006, pp. 184-188.

15. David Rohrbacher fecha a mediados del s. VI el momento en que desapareció la conciencia del tipo de trabajo historiográfico que realmente podía hallarse en la Historia Augusta, vid. Rohrbacher, 2016, p. 172: "The Historia Augusta was the product of a very specific time. The turn of the fifth century was a great era of exegesis and other forms of reflection upon texts. This style of scholarly engagement did not persist, and when the Historia Augusta is used as a source in the mid-sixth century, its distinctive allusive fictions have been systematically effaced."

16. Tantaque clementia fuit, ut et sumptu publico vulgaria funera iuberet ecferri et vano cuidam, qui diripiendae urbis occasionem cum quibusdam consciis requirens de caprifici arbore in campo Martio contionabundus ignem de caelo lapsurum finemque mundi affore diceret, si ipse lapsus ex arbore in ciconiam verteretur, cum statuto tempore decidisset atque ex sinu ciconiam emisisset, perducto ad se atque confesso veniam daret. Los textos latinos de la Historia Augusta que cito proceden de la ed. de Hohl, 1965. Las traducciones son originales. Este pasaje, aunque comparte su tono menor, queda fuera de la famosa interpolación que algunos autores han querido ver entre HA, Marc. 15, 1 y HA, Marc. 19, 12 (cf. Adams, 
En tiempos del emperador filósofo, junto a una banda de compinches, un charlatán ideó un timo para engañar a toda Roma subido a una higuera disponible para la ocasión, al parecer, en el mismísimo campo de Marte. El engaño incluía un truco para fingir la transformación del estafador en cigüeña, para lo cual, en efecto, llevaba oculta bajo sus ropas una zancuda. ${ }^{17}$

El efecto cómico de la escena no requiere mayor explicación, pero las intenciones satíricas del pasaje pueden comprenderse mejor si este episodio se asocia a algunas noticias conservadas sobre la política religiosa de Marco Aurelio. Existen varios textos jurídicos que presentan normas de Marco Aurelio tendentes a reprimir desórdenes religiosos y actitudes supersticiosas que pudieran tener alguna repercusión política. ${ }^{18} \mathrm{El}$ clemente Marco Aurelio sancionó con la deportación estos delitos. Un rescripto transmitido por Modestino y conservado en el Digesto nos ofrece el marco conceptual en el que tanto la aventura del curioso domesticador de cigüeñas de la Vita Marci, como la clemencia del emperador frente a tan extraño profeta podían resultar circunstancias absolutamente inverosímiles y ridículas para un lector informado:

Contra aquel cuyas actuaciones siembren el temor entre los espíritus humildes de los hombres con superstición religiosa [leves hominum animi superstitione numinis terrerentur], el divino Marco emitió un rescripto según el cual este debía ser deportado a una isla (Dig. XLVIII 19, 30). ${ }^{19}$

La historia de la cigüeña en la higuera, en mi opinión un comentario cómico de este texto jurídico, resume el sentido del humor que el autor de la Historia Augusta empleó en su labor de narrar en clave satírica la vida de los emperadores romanos:

2013, pp. 304-314). En esta supuesta interpolación se desarrollan episodios notoriamente fraudulentos como los amoríos de Faustina, vid. Ballesteros, 2018.

17. Si estamos hablando de la cigüeña común, el cuerpo blanco del animal podía muy bien disimularse bajo los pliegues de unos ropajes probablemente del mismo color, pero el metro de altura de los ejemplares adultos de esta especie tenía forzosamente que delatar el ocultamiento. Otro problema de no pequeña enjundia, sobre el que no nos atrevemos a aventurar hipótesis, debió plantearse cuando hubo que idear un procedimiento para mantener en calma a la pobre cigüeña mientras se producía el parlamento de su sufrido captor instalado en tan inapropiada atalaya...

18. Cf. Motschmann, 2002, pp. 144-168, que data estas medidas legales antes de la persecución del 177 d.C. (169-176 d.C.). Es posible que todas ellas remitan a una única decisión imperial.

19. Si quis aliquid fecerit quo leves hominum animi superstitione numinis terrerentur, divus Marcus huiusmodi homines in insulam relegari rescripsit. Casaubon acudió a esta cita legal en su comentario a HA, M. Ant. 23, 9, cf. Ballesteros, 2016, pp. 112-113. 
una escena irrisoria, un contenido aparentemente histórico y un mensaje crítico detrás del mismo. El guiño a la política religiosa y el cuestionamiento de la clemencia imperial que se desprenden del paralelo del rescripto del emperador, se proponen por medio de un ejercicio literario en absoluto trivial.

\section{UN POTRO EN UN TEJADO: TRABALENGUAS Y PRESAgios PARA DAR SENTIDO A LO ABSURDO}

En la Historia Augusta pueden encontrarse todo tipo resortes humorísticos. ${ }^{20} \mathrm{La}$ explosión de lo cómico en el entramado de la obra confiere a las biografías imperiales una dimensión jocosa que, más allá de lo puramente hilarante, también posee valores satíricos. Con la risa se pueden criticar vicios, representar manías y transgredir normas, es posible exponer con ella la estupidez y el sinsentido, ridiculizar los "automatismos del lenguaje" y "sortear fobias en torno a la cuestión de la muerte". ${ }^{21}$ Todos estos impulsos pueden definirse en el autor de la Historia Augusta que, mediante la burla, la polisemia y la hipérbole, practicó utopía, protesta y escepticismo. Al detectar debajo del trabajo puramente historiográfico de la Historia Augusta las formas de la sátira, el reino de lo absurdo en el que parece situarnos adquiere sentido. Para encontrar este sentido, veamos la coherencia en lo absurdo de dos episodios presentes en la narración de la Vita Pertinaci. Después de un breve reinado, la muerte le fue anunciada al emperador Pértinax por medio de varias señales:

Las señales [signa] de su muerte fueron las siguientes: tres días antes de que lo asesinaran a él mismo le pareció que se le aparecía [visus est videre] un hombre que lo amenazaba espada en mano en su piscina. El mismo día en que lo mataron decían que en sus ojos no se le veían las pupilas con el reflejo de quienes le miraban [negabant in oculis eius pupulas cum imaginibus quas reddunt spectantibus visas]. Y al hacer el sacrificio a los lares, se apagaron unas ascuas encendidas [carbones vivacissimi extincti sunt] en vez de encenderse como de costumbre [cum inflammari soleant]. Y, según dijimos más arriba, no se encontró [non est repertum] en las víctimas ni corazón ni molleja. El día antes de

20. Cameron, 2011, p. 778 los resume en los siguientes: la cita de autores fingidos, los documentos fraudulentos, los personajes inventados, los poemas falsos, los chistes estúpidos, los trabalenguas infantiles, los temas recurrentes (adopción, eunucos, emperadores niños), la fascinación por la comida, la bebida y la ropa.

21. Estas son las funciones de lo cómico según D’Angeli y Paduano, 2001. 
morir se vio con toda claridad durante el día [per diem clarissimae visae] estrellas al lado del sol (HA, Pert. 14, 1-3).22

El pasaje reúne una repetitiva acumulación de conceptos relacionados con la percepción y la representación de la realidad. Es un juego de palabras con el que se expone una alteración generalizada en el proceso de la percepción del propio Pértinax y de su entorno. La realidad y la apariencia se confunden en los días previos a su muerte violenta. El predominio en todo el texto de los términos relacionados con la representación de la realidad (signa, imago, video...) nos instala en un mundo de dudas y contribuye a diluir las fronteras de la certeza. En estos momentos decisivos de la biografía de Pértinax, los procedimientos de percepción (por lo general visual) dejan de ser fiables. La confusión impera en torno al emperador y se multiplican los giros lingüísticos que vienen a subrayar el reflejo, la incertidumbre, lo absurdo y lo inverosímil que parece percibirse. Los presagios con los que la Historia Augusta anuncia la muerte inminente de Pértinax nos dejan en un ambiente confuso donde, $\tan$ desorientados como el propio protagonista de la biografía, debemos renunciar a la seguridad de los hechos para adoptar la más fluida compañía de su representación. Por momentos, las percepciones adquieren el formato de inciertas ensoñaciones. El del emperador es un mundo inconsistente, etéreo y escurridizo. Del mismo modo, el lenguaje que nos lo representa queda al margen de lo real y de lo constatable. Por eso, para acceder al universo huidizo de la biografía imperial nada mejor que las fórmulas de la ficción.

Señales que sustituyen a los hechos y reflejos que, tomados por certezas, contribuyen a la confusión. Todo invita a suspender el juicio, un requisito, en suma, para aceptar la historicidad que nos proporciona el estrambótico relato de la Historia Augusta. Pértinax, cuyo final se anunció de unos modos tan irreales, nació en circunstancias también bastante extravagantes. En aquella señalada ocasión, su padre decidió consultar a un adivino sobre el significado de cierto hecho singular acaecido en el mismo instante de su nacimiento:

22. Signa interitus haec fuerunt: ipse ante triduum quam occideretur in piscina sibi visus est videre hominem cum gladio infestantem. Et ea die, qua occisus est, negabant in oculis eius pupulas cum imaginibus, quas reddunt spectantibus, visas. Et cum apud lares sacrificaret, carbones vivacissimi extincti sunt, cum inflammari soleant. Et, ut supra dictum est, cor et caput in hostiis non est repertum. Stellae etiam iuxta solem per diem clarissimae visae ante diem quam obiret. 
Pértinax nació en la residencia de su madre en el Apenino. A la misma hora en que nació, un potro se subió a un tejado, allí permaneció por un momento, se cayó y se mató. Por esta razón acudió el padre a un caldeo que después de predecirle las grandes cosas que le habían de suceder al niño, le dijo que había malgastado su dinero (HA, Pert. 1, 2-3). ${ }^{23}$

La visita al caldeo del padre de Pértinax tras el excepcional episodio del potro en el tejado es una de las muchas noticias absurdas y sorprendentes con que la Historia Augusta adorna sus biografías. Por lo general han servido para describir, de nuevo, el trabajo frívolo de un historiador incompetente. ${ }^{24}$ Pero si en lugar de reconstruir la endeblez del método historiográfico de su autor que habría elaborado esta noticia para explicar la brevedad y el final traumático del imperio de Pértinax, pensamos el episodio desde la perspectiva de una intención satírica, el significado del pasaje se enriquece. Los valores que se le pueden atribuir (estupidez, necedad) dejan de calificar la pobre credulidad del historiador que los recoge y pasan a calificar la actitud del padre del emperador que decidió malgastar su dinero contratando los servicios de un adivino caldeo para que le interpretara la peregrina circunstancia del ascenso y caída del potro del tejado. Algo tan necio como la propia pretensión de querer predecir el futuro de un recién nacido a partir de aquel pintoresco suceso.

\section{El espejo de Didio Juliano: materiales literarios para la FICCIÓN HISTORIOGRÁFICA}

Regresemos al incierto mundo de las representaciones. Didio Juliano fue, como Pértinax, un emperador efímero. Tras dos meses de reinado fue depuesto por el Senado y ajusticiado el 1 de junio del 193. De esta manera concluía la vida de un consular de 60 años que había hecho su carrera política al servicio de Marco Aurelio. ${ }^{25}$ Reconstruir

23. Natus est Pertinax in Appennino in villa matris. Equus pullus ea hora, qua natus est, in tegulas ascendit atque ibi breviter commoratus decidit exspiravit. Hac re motus pater ad Chaldaeum venit. Qui cum illi futura ingentia praedixisset, stipem se perdidisse dixit. Creo que esta versión es preferible a la variante stirpem se perdidisse dixit (le dijo que su linaje se había malogrado), posiblemente una lectio facilior frente al texto traducido. La lectura stirpem, no obstante, está presente en la mejor tradición ms. de la Historia Augusta. Mayer I Olivé, 2014, pp. 335-340 analiza este pasaje y ofrece argumentos convincentes para descubrir en él "un resabio de tradición popular y un contenido proverbial" (p. 339).

24. Es una opinión frecuente, por ejemplo, en Binaghi Fasce, 1998, p. 3: "activitat que si volem podem qualificar de menor, caduca, superficial o gens interessant.”; o en Cameron, 2011, p. 781: "El autor de la Historia Augusta era un tipo frívolo e ignorante sin tan siquiera intenciones merecedoras de tal nombre [de historiador]."

25. La fuente antigua más solvente sobre Didio Juliano es Herod., II 6-12. Sobre su breve reinado Le Gall y Le Glay, 1995, pp. 447-448. 
la personalidad de este emperador sigue siendo un proyecto sumamente especulativo. La propuesta del autor de la Historia Augusta, por espectacular, ha adquirido un valor casi definitivo en este sentido. En efecto, la Historia Augusta da detalles muy precisos sobre las costumbres de Didio Juliano, un emperador que ha adquirido el perfil de fervoroso practicante de novedosos rituales y artes mágicas. ${ }^{26}$

La adivinación y la magia son asuntos recurrentes en la Historia Augusta. Rara es la biografía sin astrólogo. Muchos emperadores fueron, de hecho, adivinos sobresalientes. Adriano, peritus matheseos, consultaba adivinos desde antes de llegar al poder y, gracias a sus habilidades mánticas, realizaba previsiones anuales y horóscopos durante su reinado ( $\mathrm{Hadr} .2,3-4,16,7$; Ael. 3, 8-9). Naturalmente en el variopinto entorno del emperador no faltaban los astrólogos (Hadr. 16, 10). De modo similar, Septimio Severo, matheseos peritissimus, frecuentó antes de llegar al poder a adivinos caldeos en Sicilia, lo cual le causó algún problemilla con la justicia (Sev. 3, 9; 4, 3). Los horóscopos le ayudaron a elegir esposa y su propio poder adivinatorio le permitió prever su victoria en la guerra civil (Sev. 3, 9; 9, 5-6). Alejandro Severo era un especialista consumado en cualquier mecanismo adivinatorio: matheseos peritus, haruspicinae quoque peritissimus, orneoscopos magnus. Con estas habilidades era capaz de superar a los augures panonios y a los vascos (Alex. Sev. 27, 5). La figura de Didio Juliano constituye una versión extrema de las inclinaciones mánticas de la institución imperial retratada por la Historia Augusta:

Afectaba particularmente a Juliano la locura de querer llevar a cabo todos sus asuntos con la intermediación de magos. Pensaba que con su ayuda era capaz de mitigar el odio del pueblo y evitar revueltas militares. Inmolaron [los magos y Didio Juliano] víctimas impropias para los rituales sagrados romanos, realizaron hechizos con conjuros profanos y Juliano llegó a practicar lo que se hace ante un espejo en el que se dice que niños a los que se les han vendado los ojos y hechizado el entendimiento ven cosas. Se dice que entonces un niño vio la entrada de Severo en la Ciudad y la huida de Juliano (HA, Did. Iul. 7, 9-11). ${ }^{27}$

26. Cf. Cass. Dio, LXXIII 16, 5, que explica que Didio Juliano practicó sacrificios infantiles para conocer el futuro. Esta noticia posiblemente está en el origen de toda la construcción de la Historia Augusta.

27. Fuit praeterea in Iuliano haec amentia, ut per magos pleraque faceret, quibus putaret vel odium populi deleniri vel militum arma conpesci. Nam et quasdam non convenientes Romanis sacris hostias immolaverunt et carmina profana incantaverunt et ea, quae ad speculum ducunt fieri, in quod pueri praeligatis oculis incantato vertice respicere dicuntur, Iulianus fecit. Tuncque puer vidisse dicitur et adventum Severi et Iuliani decessionem. Tuczay 2002, un trabajo del que he tenido noticia gracias al informe de uno de los 
Desde el punto de vista sintáctico el pasaje es bastante confuso. Las tres iniciativas mágicas que se comentan están coordinadas por el copulativo et [et ... inmolaverunt, et ... incantaverunt, et ... fecit] con lo que es posible suponer algún tipo de correlación en las mismas, pero el sujeto gramatical de las dos primeras acciones es distinto del de la tercera. En los dos primeros casos el plural parece encubrir a los magi empleados por Didio Juliano. En el tercero, el sujeto explícito es el propio emperador. No obstante, la construcción del período, que se cierra con Iulianus fecit, parece conferir al emperador el mismo protagonismo en la puesta en práctica de sacrificios e invocaciones mágicas que el que tiene abiertamente en el desarrollo de la ceremonia adivinatoria final. Las traducciones que se han dado de este pasaje no alteran sustancialmente esta fórmula. ${ }^{28}$

Isaac Casaubon, que dedicó un extenso comentario al texto, creyó ver en las iniciativas de Didio Juliano para asegurarse la buena voluntad del pueblo [quibus putaret odium populi deliniri] un trasunto de las técnicas propiciatorias de los amarres amorosos. ${ }^{29}$ Entendió aquellas "víctimas impropias para los rituales sagrados romanos" [quasdam non convenientes Romanis sacris hostias] como el sacrificio de niños, y los "conjuros profanos" [carmina prophana] como fórmulas mágicas bárbaras introducidas contra la tradición romana. El colofón de tan sabrosos hábitos mágico-religiosos, el elemento más interesante de todos los rituales practicados por el emperador y su entorno de magos, es el uso de un espejo mágico. Casaubon tam-

revisores anónimos de este trabajo, utiliza tangencialmente este texto en su estudio de los "Wahrsagende Medien" (p. 39).

28. Calvo Navarro, 1919, pp. 229-230: "Juliano llevó la demencia hasta mandar operaciones mágicas destinadas a calmar el odio popular y a inutilizar las armas de sus enemigos, hizo sacrificios contrarios a la religión romana y cantó versos profanos. En seguida recurrió a esa manera de adivinación que se hace por medio de un espejo, detrás del cual, niños cuyas cabezas y brazos se han sometido a ciertos encantamientos, leen el porvenir. Preténdese que el que eligió, vio la llegada de Severo y la retirada de Juliano"; Picón y Cascón, 1989, p. 223: "Juliano tuvo además la insensatez de utilizar a los magos para celebrar muchos ritos con los que pensaba aplacar el odio del pueblo o apaciguar la exaltación bélica de los soldados. En efecto, los magos sacrificaron algunas víctimas que no eran adecuadas para los ritos romanos y cantaron himnos profanos y Juliano hizo los ensalmos que, según las prescripciones, se hacen ante un espejo, en el que dicen que los niños ven el futuro, después de haber vendado sus ojos y haber pronunciado fórmulas mágicas sobre su cabeza, y en aquella ocasión se dice que un niño vio la llegada de Severo y la retirada de Juliano."; Chastagnol, 1994, p. 295: "Julianus, pour sa part, était pris d'une telle folie, qu'il faisait accomplir par des mages beaucoup de rites grâce auxquels il espérait apaiser la haine du peuple ou arrêter les soldats en armes. C'est ainsi qu' ils immolaient des victimes étrangères au culte romain et chantaient des formules magiques sur leur tête. On raconte qu' un enfant [y] vit alors l'arrivée de Sévère et le départ de Julianus."

29. Casaubon, 1603, p. 250: exemplo videlicet ab amantibus petito. Notae sunt artes $\varphi$ i $\lambda \tau \tau \omega v$ conficiendorum, de quibus multa Graeci passim ac Latini. 
bién dedicó un amplio excursus a esclarecer los antecedentes y paralelos del arte de adivinar por medio de los espejos.

La catoptromancia es la disciplina mántica que emplea un espejo para ver hechos pasados, presentes o futuros. También permite identificar enemigos, observar lugares lejanos, identificar practicantes de otras disciplinas mágicas e invocar y, en su caso, encerrar a demonios y malos espíritus. ${ }^{30}$ Como se ve, la virtud reveladora del espejo hace de él un objeto muy apropiado para el afloramiento de hechos ocultos. Como muchas otras artes adivinatorias de carácter alucinatorio se fundamenta en las revelaciones que llegan a personas particularmente receptivas (videntes) por mediación de diversos procedimientos con los que se excita su facultad profética. Estos procedimientos conectan al vidente con potencias sobrenaturales. Frente a la mántica alucinatoria, las prácticas de adivinación ominal, tradicionales en la religión romana, consistían en interpretar signos precisos contemplados en la naturaleza según procedimientos relativamente estandarizados. Este modelo adivinatorio es el que se encuentra detrás de la afirmación presente en el texto citado más arriba sobre la ausencia de corazón y molleja en los sacrificios que precedieron al asesinato de Pértinax. En la religión romana, sacerdotes especialistas según la tradición etrusca (arúspices) eran los encargados de practicar los sacrificios y observar esas entrañas. En otras modalidades ominales, el vuelo y otros comportamientos de ciertas aves eran objeto de interpretación por parte de los augures. ${ }^{31}$

En la descripción que de la experiencia catoptromántica se da en la Historia Augusta, la función de médium se confiere a unos niños. Una variante expuesta por Casaubon, bastante improbable desde el punto de vista textual pero presente en una rama de la tradición manuscrita de la Historia Augusta, contemplaba la posibilidad de que esa función la desempeñara un solo niño. ${ }^{32}$ Estos muchachos, en un estado de trance [incantato vertice], desarrollaban ante un espejo [ad speculum] algún tipo de observación [respicere]. De un modo algo incoherente - en la medida que semejante práctica pueda ser explicada de modo coherente - pero con paralelos en la literatura mágica antigua, los jóvenes catoptromantes de Didio Juliano desarrollaban su técnica

30. Delatte, 1932 sigue siendo una obra esencial sobre este asunto. Carrington Bolton, 1893, pp. 25-37 constituye un bonito precedente que, desde mi punto de vista, aún merece ser leído.

31. Todos estos asuntos han estado presentes en el análisis del pasaje. Lupanus [= Vincent de la Loupe], 1560, 30rv cita el Commentarius de praecipuis divinationum generibus (1593) de Gaspar Peucer (1525-1602), yerno de Melanchthon. Sobre los procedimientos ominales véase un tratamiento sintético en Contreras Valverde, Ramos Acebes y Rico Rico, 1992, s.v. 'Arúspices', p. 12, s.v. 'Augures', pp. 14-15.

32. Casaubon, 1603, 250: Regius [Parisinus 5807] ea quae dicunt ad speculum fieri, in eodem puer non pueri, quia sequitur puer vidisse dicitur sed melius pueri ob sequens verbum dicuntur. 
con los ojos tapados [praeligatis oculis]. El texto no deja claro si este requisito debía mantenerse durante toda la ceremonia o sólo en el momento previo a la misma. ${ }^{33}$

La participación de niños, de espíritu puro y por ello más apropiados para el tipo de comunicación previsto en esta práctica, es común en el desarrollo de la catoptromancia especuladora antigua y moderna. En ocasiones, también formaba parte del ritual el susurro a la oreja de los chiquillos de palabras y fórmulas misteriosas que propiciaran el acto adivinatorio. ${ }^{34}$ Estas fórmulas de evocación y sugestión consistían en una extraña terminología greco-egipcia. En época bizantina se incorporaron oraciones cristianas. Es posible que los carmina prophana del pasaje de la Historia Augusta aludan a esta práctica.

El relato de la Historia Augusta reúne, pues, en extraña mescolanza varios elementos propios de las técnicas mánticas antiguas. Es significativo, a mi modo de ver, que en el pasaje de la Historia Augusta, el comentario se limite a una descripción exclusivamente formal, y algo confusa, del procedimiento adivinatorio practicado en el entorno imperial. Poco o nada se dice de las consultas planteadas por Didio Juliano. La visión del niño con la que concluye el pasaje [Tuncque puer vidisse dicitur...] no deja de ser un colofón algo forzado para dotar de cierta verosimilitud histórica a todo el episodio adivinatorio. Toda la información técnica sobre la catoptromancia estaba, sin duda, disponible gracias a una literatura específica que se nos ha conservado parcialmente en la forma de papiros adivinatorios. ${ }^{35}$ La Historia Augusta procedió a la reelaboración de noticias procedentes de estos bajos fondos literarios en el pasaje de la Vita Didii Iuliani y, en cierto modo, subrayó lo absurdo y ridículo (como, por ejemplo, la observación del espejo praeligatis oculis).

Todos estos materiales - existen otros extraños y dudosos procedimientos adivinatorios en la Historia Augusta $-{ }^{36}$ se incorporaron a un discurso que posee la as-

33. Delatte, 1932, p. 141: "Les magiciens des papyrus voilent souvent les yeux du médium pendant les préparatifs de la lécanomancie [diversos procedimentos mánticos que requieren de un cuenco: analizar el sonido de piedras preciosas arrojadas al cuenco, observar las formas que adopta aceite vertido sobre el agua del cuenco...], pour les découvrir brusquement au moment opportun"; ibid., p. 198: "Les yeux de l’enfant qui sert de médium sont tenus fermés jusqu’à ce que tous les préparatifs soient terminés; on lui permet alors de regarder dans l'eau et il a une vision de dieu."

34. Delatte, 1932, p. 59 (y passim).

35. Sobre los cuales Brashear, 1995, pp. 3380-3684, ofrece una visión de conjunto. De un modo más monográfico Gordon, 1997, pp. 65-91 y 1999, pp. 161-275.

36. Por ejemplo, las enigmáticas vergilianae sortes (Hadr. 2, 8) sobre las que Cameron, 2011, pp. 608609 ha elaborado juicios bastante escépticos (y convincentes). Algo similar puede ocurrir con los vaticinios de los perros (vaticinationibus canum) del templo de Caelestis (Pert. 4, 2). Este canum, lectura propuesta por Gilbert Charles Picard en un trabajo de 1959 frente al earum de los ms., se explica como la 
piración de volver cotidiano lo exótico. Y para conseguirlo de nuevo se hace preciso lograr que un lector aturdido por extrañas formulaciones se sienta desorientado en el desarrollo de la lógica narrativa. De nuevo la descripción de los hábitos mágicos de Didio Juliano emplea fórmulas gramaticales que huyen de la certeza y de una exposición de hechos que se sustente en testimonios de primera mano. Se prefieren fórmulas indirectas que siembran la duda [rescipere dicuntur, vidisse dicitur]. En la Historia Augusta debemos acostumbrarnos a frecuentar lo extraño y lo disparatado a través del testimonio siempre indirecto detrás del cual el autor se esconde.

\section{La máscara de Heliogábalo: Retratos de PrínCipes, Refugio del ERUDITO IMPERTINENTE}

Las técnicas cómicas de la Historia Augusta se perciben nítidamente en el momento en el que su autor se dispone a retratar a los príncipes. Al presentar el físico, el carácter y las costumbres del emperador, la Historia Augusta manifiesta, de nuevo, su plan para provocar una risa carnavalesca. Esta vez el método consiste en caricaturizar fisionomías y personalidades. Las contradicciones internas de estas descripciones subrayan el gusto por lo equívoco de un registro literario que se vuelve subversivo en tanto que ácrata: el refugio de un erudito de vocación iconoclasta. En la Historia Augusta, los emperadores romanos se convierten en figuras triviales, marginales por momentos, el testimonio de que "el inexorable ciclo de lo absurdo" en el que la Historia Augusta ha transformado la narración de la historia imperial de los ss. II y III puede funcionar como crítica.

La estructura de estas descripciones cómicas es regular y redundante: rasgos contradictorios morales y físicos del personaje se suceden en quiasmo para regocijo (o pasmo) del lector. Por ejemplo, en la definición de Adriano, presumiblemente derivada del retrato célebre del emperador que da el Epítome de ps-Aurelio Víctor (14, $6),{ }^{37}$ se alternan conceptos que hacen que Adriano sea realmente inaprensible:

pervivencia en el templo de Caelestis de Cartago de personal "de tradición semítica” (canes) con carisma adivinatorio, cf. Picard, 1959, p. 50. Si se admite la lectura canum pueden darse otras explicaciones al pasaje, por ejemplo, a partir de Prop., IV 8, 45-46 se puede deducir una alusión, dado que "perro" era una de las posibles jugadas de la suerte de las tabas que también se empleaba con fines adivinatorios (cf. Delrio, 1679, p. 593 y la nota de Tovar y Belfiore Mártire, 1984, p. 227, n. 11). Los "perros pronosticadores" también pudieran haber surgido de un juego de palabras procedente de vates Caelestis apud Carthaginem quae dea repleta solet vera canere (Opil. Macr. 3, 1).

37. Varius, multiplex, multiformis ad vitia atque virtutes quasi arbiter genitus. 
Era a la misma vez serio y chistoso, cercano y distante, lanzado y reservado, obstinado y dejado, <iba de frente y tenía dobleces, era cruel y clemente, en fin, que nunca había por dónde cogerlo (HA, Hadr. 14, 11). ${ }^{38}$

Del mismo modo y con el mismo formato, Avidio Casio, cuius ipsius mores... varii semper fuerunt (HA, Avid. Cass. 13.8), aparece como un personaje de personalidad e inclinaciones paradójicas y contradictorias:

Por sus costumbres, aunque había ocasiones en que pudiera parecer osco y áspero, en otras era dulce y delicado, devoto con frecuencia, impío otras veces, borracho y abstemio a la vez, adoraba la comida y aguantaba el ayuno, era promiscuo y amante de la castidad (HA, Avid. Cass. 3, 4). ${ }^{39}$

En la caracterización de los emperadores, la religión es un elemento más en el juego de ironías que plantea la Historia Augusta. Es el caso, por ejemplo, del retrato de Pescenio Níger, un emperador de imagen sorprendente y, de nuevo, contradictorio carácter. Al inicio de su biografía aparece como "medianamente leído, de costumbres primitivas, inmoderadamente rico, de vida austera, dado a todo tipo de desenfrenos en sus deseos" (HA, Pesc. Nig. 1, 4). ${ }^{40}$ Más adelante, para precisar su sorprendente imagen se aportan algunas noticias de naturaleza religiosa:

Era alto, hermoso, de bonita melena peinada hacia atrás [statura prolixa, forma decorus, capillo in verticem ad gratiam reflexo]. Tenía la voz ronca, pero melodiosa, si hablaba en campo abierto [in campo loquens] se le oía a mil pasos, siempre que no lo hiciera de cara al viento, la vergüenza se le veía en la cara, siempre estaba colorado [oris verecundi et semper rubidi]. Tenía el pescuezo tan negro [cervice adeo nigra] que, tal cual muchos dicen, por eso le pusieron Níger. En el resto del cuerpo era pálido y algo gordito. Era aficionado al vino, de poco comer, no estaba en absoluto interesado por el sexo si no era para tener descendencia. Por lo demás, tomó a su cargo con el

38. Idem severus laetus, comis gravis, lascivus cunctator, tenax liberalis, <simplex $>$ simulator, saevus clemens et semper in omnibus varius. Sobre este texto y los intentos de restitución (aquí adopto el de H. S. Reimarus), vid. Fündling, 2006, pp. 719-736.

39. Fuit his moribus, ut nonnumquam trux et asper videretur, aliquando mitis et lenis, saepe religiosus, alias contemptor sacrorum, avidus vini item abstinens, cibi adpetens et inediae patiens, Veneris cupidus et castitatis amator.

40. Hic eruditus mediocriter litteris, moribus ferox, divitiis inmodicus, vita parcus, libidinis effrenatae ad omne genus cupiditatum. Chastagnol, 1994, p. 354, n. 5 señala la contradicción de esta descripción con el siguiente retrato del mismo personaje. 
beneplácito de todo el mundo la celebración de ciertos rituales típicos de Galia que se ofician para personas castísimas [Denique etiam sacra quaedam in Gallia, quae castissimis decernunt, consensu publico celebranda suscepit]. Lo vemos en el pórtico curvo de los jardines de Cómodo representado en un mosaico entre los mejores amigos de Cómodo llevando los objetos sagrados del culto a Isis [Hunc in Commodianis hortis in porticu curva pictum de musio inter Commodi amicissimos videmus sacra Isidis ferentem] (HA, Pesc. Nig. 6, 5-8). ${ }^{41}$

Para retratar a Pescenio Níger, la Historia Augusta ha desplegado todo su repertorio de imágenes peyorativas, fórmulas burlonas, combinaciones contradictorias y alusiones implícitas. Inicialmente se emplean conceptos con ciertas reminiscencias sexuales para describir el aspecto físico y el rostro del emperador. ${ }^{42}$ En seguida, se utiliza la imagen del epónimo "pescuezo negro" del emperador que puede asociarse tanto a la paródica descripción física anterior como a la afición al vino que la biografía le atribuye inmediatamente. ${ }^{43}$ A las credenciales anatómicas de Pescenio y a su alusivo porte le siguen dos comentarios sobre su vida religiosa. A este emperador se le encargó, consensu publico, la dirección de unos ritos propios de Galia quae castissimis decernunt, muy probablemente una referencia al culto de Magna Mater en el que participaban unos sacerdotes castrados llamados galli. ${ }^{44}$ Esta referencia sirve para completar la anterior descripción física del emperador: es una manera bastante irónica para referirse al emperador como eunuco. En segundo lugar, se comenta una

41. Fuit statura prolixa, forma decorus, capillo in verticem ad gratiam reflexo, vocis raucae sed canorae, ita ut in campo loquens per mille passus audiretur, nisi ventus adversaretur, oris verecundi et semper rubidi, cervice adeo nigra, ut, quemammodum multi dicunt, ab ea Nigri nomen acceperit, cetera corporis parte candidus et magis pinguis, vini avidus, cibi parcus, rei veneriae nisi ad creandos liberos prorsus ignarus. Denique etiam sacra quaedam in Gallia, quae castissimis decernunt, consensu publico celebranda suscepit. Hunc in Commodianis hortis in porticu curva pictum de musio inter Commodi amicissimos videmus sacra Isidis ferentem.

42. La estatura prolixa, el capillo in verticem ad gratiam reflexo, la vox rauca ... in campo loquens, oris verecundus [...] semper rubidus, la cervix nigra y el cuerpo candidus et magis pinguis pueden generar una serie de asociaciones con el órgano sexual masculino. Adams, 1982, pp. 9-79 recorre el amplísimo campo semántico asociado al órgano masculino, dentro del cual se encuentra "verecunda" (ibid., pp. 5455), el color rojo del mismo es lugar común (ibid., p. 65), así como la personificación del órgano sexual masculino (ibid., p. 72). Del mismo modo, el acto sexual puede explicarse con todo tipo de metáforas de índole agraria: cavar, arar, segar (ibid., pp. 151-155) de modo que el órgano femenino se convierte en ager.

43. Cervix puede significar cuello, gañote o pescuezo, también es el cuello de una botella, cf. Mart., Epigr. 12, 32.

44. El profesor Jaime Alvar, que me facilitó la referencia al culto de Magna Mater, me ha ayudado a entender toda la profundidad satírica que subyace bajo los juegos irónicos del pasaje. 
representación iconográfica del propio emperador en una procesión isíaca [sacra Isidis ferentem]. La religión isíaca, sobre cuya misteriosa iconografía la literatura latina ofrece significativos juicios sarcásticos, ${ }^{45}$ acentúa por su parte el carácter irrisorio de la descripción de Pescenio Níger. ${ }^{46}$

De todas las máscaras con las que la Historia Augusta representa - y, a mi juicio, descalifica - a una larga nómina de emperadores romanos, la que tiene un mayor contenido religioso es la de Heliogábalo. Al emperador sirio se le responsabiliza de importantes novedades religiosas. Buena parte de la información que ilustra estas novedades procede de la Historia Augusta. ${ }^{47}$ En toda la pirotecnia religiosa que la obra atribuye a Heliogábalo es posible rastrear intenciones burlescas y, consecuentemente, críticas.

Mezcla de histrión teatral, maníaco panreligioso y obseso nudista, Heliogábalo es el protagonista de una de las narraciones más inverosímiles de la colección. ${ }^{48} \mathrm{~A}$ lo largo de su biografía, la hiperactividad religiosa del emperador está acompañada por una similar exposición a la actividad sexual. En el fanático desarrollo de ambas obsesiones, el personaje de Heliogábalo adquiere un perfil característico. En medio de una extenuante búsqueda de definición erótico-religiosa para sí mismo y para la función imperial que desempeña, el emperador deviene en actor capaz de asumir cualquier identidad:

Representaba por lo demás en su casa el cuento de Paris desempeñando él mismo el papel de Venus. Actuaba del siguiente modo: sus ropas se deslizaban súbitamente hasta el suelo y quedaba desnudo, con una mano se tapaba su pecho y con la otra sus partes pudendas, se arrodillaba y ofrecía el trasero en pompa que quedaba a disposición del otro actor [o de su pareja homosexual: in subactorem]. Modelaba además su rostro con la misma expresión con que se pinta a Venus, se depilaba el cuerpo entero y estimaba que la principal recompensa de la vida consistía en ser considerado digno de satisfacer los caprichos de cuantos más mejor (HA, Heliogab. 5, 4-5). ${ }^{49}$

45. Sobre los cultos egipcios, Alvar, 2001, pp. 216-254. Los profs. Jaime Alvar, Valentino Gasparini y Elena Muñiz me han proporcionado varias referencias sobre la percepción antigua, por lo general peyorativa, de los cultos egipcios (Juv., VI 532-541; Prop., II 33, 1-6; Sen., De superst. ap. August., C.D. VI 10, 2 , entre otros). Sirva esta nota, como la anterior, de reconocimiento por sus interesantes apreciaciones al respecto.

46. Sobre la mezcla de ritos tan del gusto del autor de la Historia Augusta, vid. Bertrand-Dagenbach, 2014, pp. 31-39 y los párrafos que siguen sobre el retrato de Heliogábalo.

47. En general, Optendrenk, 1969, que comenta varios pasajes retomados en este trabajo.

48. Sobre la definición historiográfica de Heliogábalo, Bittarello, 2011, pp. 93-113.

49. Agebat praeterea domi fabulam Paridis ipse Veneris personam subiens, ita ut subito vestes ad pedes defluerent, nudusque una manu ad mammam altera pudendis adhibita ingenicularet posterioribus eminentibus in subactorem reiectis et oppositis. Vultum praeterea eodem, quo Venus pingitur, schemate 
Heliogábalo ha convertido el servicio estoico a la comunidad propio de la institución imperial - "gloriosa forma de esclavitud" según la mejor tradición griega sobre la monarquía, Ael., VH 2, 20 - , en un trabajo arduo con el que dar satisfacción a todo tipo de cultos, rituales y requisitos religiosos [eum fructum vitae praecipuum existimans, si dignus atque aptus libidini plurimorum videretur]. Por su propia voluntad, los servicios imperiales acabaron incluyendo también la práctica de la prostitución por parte del propio emperador.

El Heliogábalo de la Historia Augusta es también una figura relevante para entender el valor determinante que la religión había adquirido en las políticas imperiales de integración política y la crítica que de las mismas se podía hacer. En la Historia Augusta, la biografía de Heliogábalo permite a su autor construir una versión sublimada de esta realidad. El emperador propone un proceso de integración imperial basado en un monopolio omnímodo del espacio religioso. Poco importan confusiones rituales y errores formales, la voluntad imperial es amalgamar la experiencia religiosa universal, reunir bajo su manto sin límites la biodiversidad religiosa que se pueda allegar desde todos los rincones de su Imperio. Su objetivo es diluir todas las fronteras y hacer del Imperio romano un lugar para todas las especies, un zoológico en el que, si logra sobrevivir al impacto de la asimilación, hasta la más exótica tiene cabida:

Procesionó públicamente incluso tirado por cuatro enormes ciervos. Lo hizo también con un tiro de leones y se daba entonces el nombre de Magna Mater. También fue tirado por tigres, entonces era Líber. Se vestía igual que se pinta en los cuadros a los dioses que él imitaba. Tuvo en Roma serpientes egipcias, las llamadas "espíritus bondadosos". También tuvo hipopótamos, un cocodrilo, un rinoceronte y todos los animales de Egipto que pudieron aguantar el traslado al zoo. En alguna ocasión ofreció en los banquetes avestruces con el argumento de que era un alimento obligatorio para los judíos (HA, Heliogab. 28, 2). ${ }^{50}$

figurabat corpore toto expolitus eum fructum vitae praecipuum existimans, si dignus atque aptus libidini plurimorum videretur.

50. Processit in publicum et quattuor cervis iunctis ingentibus. Iunxit sibi et leones, Matrem magnam se appellans. Iunxit et tigres, Liberum sese vocans eodemque habitu agens, quo dii pinguntur, quos imitabatur. Aegyptios dracunculos Romae habuit, quos illi agathodaemonas vocant. Habuit et hippopotamos et crocodillum et rhinocerotem et omnia Aegyptia, quae per naturam sui exhiberi poterant. Struthocamelos exhibuit in cenis aliquotiens, dicens praeceptum Iudaeis, ut ederent. La carne del avestruz no es kosher porque es un animal impuro y no comestible. Según Syme, 1971, p. 26, esta nota denuncia de nuevo el sentido del humor del redactor de la Historia Augusta. Del mismo modo, Chastagnol, 1994, p. 534, n. 7: "une invention humoristique du rédacteur". 
El ideal integrador, cosmopolita e igualador que de un modo muy sui generis la Historia Augusta atribuye a Heliogábalo no excluye la prioridad satírica que aporta un sentido decadente, vergonzante y ridículo a la obra integradora del príncipe:

A muchos cuyos cuerpos le placían los sacó del teatro, del circo y de la arena para llevarlos a la corte. A Hierocles lo amó hasta el extremo de besarle directamente la entrepierna [ut eidem inguina oscularetur], sólo decirlo resulta vergonzoso, y reivindicaba que este era el modo que él tenía de celebrar los rituales de las Florales (HA, Heliogab. 6, 4-5). ${ }^{51}$

Inguina osculare es, sin lugar a dudas, un procedimiento radical de integración y servicio público. De hecho, vincula los esfuerzos integradores de Heliogábalo a unos precedentes históricos y literarios concretos. Nerón también se lanzaba en busca de órganos sexuales en actuaciones más o menos teatrales en las que, de nuevo, comparecía con un favorito y adoptaba posiciones vergonzantes, indignas de la institución imperial que representaba. ${ }^{52}$ Con Heliogábalo sátira y crítica quedan unidas de modo sintético. En la biografía que la Historia Augusta le dedica, el discurso político romano altoimperial al que Plinio había dado una forma canónica en el Panegírico de Trajano es satirizado y, en buena medida, demolido. Creo que Heliogábalo es el personaje que mejor parodia en toda la Historia Augusta las funciones y los fracasos del emperador. ${ }^{53}$

51. Multos, quorum corpora placuerant, de scena et circo et harena in aulam traduxit. Hieroclen vero sic amavit, ut eidem inguina oscularetur, quod dictu etiam inverecundum est, Floralia sacra se adserens celebrare. Vid. Optendrenk, 1969, pp. 25-29 y las notas correspondientes 19 a 26, en las que reúne varias citas que explican con qué tipo de comportamientos sexuales se celebraban las fiestas Florales en Roma.

52. Suet., Ner. 29: [...] quo ferae pelle contectus emitteretur e cavea virorumque ac feminarum ad stipitem deligatorum inguina invaderet et, cum affatim desaevisset, conficeretur a Doryphoro liberto, cui etiam, sicut ipsi Sporus, ita ipse denupsit, voces quoque et heiulatus vim patientium virginum imitatus, "[...] hacía que lo soltaran de una jaula cubierto con una piel de fiera y se precipitaba sobre los órganos sexuales de hombres y mujeres atados a unos postes y después de haber saciado sus crueles instintos se hacía cubrir por su propio liberto Doríforo, a quien servía de mujer, como Esporo a él, imitando en tales ocasiones los gritos y los gemidos de las mujeres al ser violadas" (trad. Bassols de Climent, 1964-1970).

53. Por ello encuentro excesivamente mecánico el intento de identificar el Heliogábalo retratado en la Historia Augusta con emperadores concretos del s. IV, cf. Turcan, 1986, que establece varias analogías entre Heliogábalo y Constantino (la devoción solar, la acusación de impietas, el exclusivismo religioso, la indignidad de sus madres, los nombramientos de personas poco dignas de su entorno, la iconografía imperial, la gastrolatría "sofisticada y teatral") o Ratti, 2014, pp. 431-432: “Héliogabale et, derrière lui, en ombres chinoises Constantin et Théodose”. Creo, en cambio, que el Heliogábalo de la Historia Augusta es la pieza con la que la obra expresa las angustias generadas por la redefinición de la identidad romana a que la proyección imperial del Estado y la sociedad dio lugar. Este mismo asunto ha sido estudiado en Juvenal y Tácito (vid. Shumate, 2006 y Pagán, 2017). 


\section{APÉNDICE: ESPACIO PÚBLICO Y ESPACIO RELIGIOSO, CRISTIANOS EN LA Historia Augusta}

Además de la de identificar retruécanos cómicos y juegos de palabras, la Historia Augusta ofrece al lector curioso la posibilidad discutir el sentido de significativos silencios. El cristianismo ha dejado un rastro tan tenue en la Historia Augusta que bien merece ser tenido por uno de esos temas silenciados. Anthony R. Birley ha identificado una decena de referencias explícitas al cristianismo en la Historia Augusta, además de otras cinco en que se menciona a judíos y que, eventualmente, podrían encubrir también alusiones a los cristianos. ${ }^{54}$ Todas estas referencias son tan vagamente secundarias que resulta difícil establecer claramente cuál es la postura de la colección frente a la nueva fe. Reivindicación de tolerancia, admiración por ciertas prácticas y principios cristianos - HA, Alex. Sev. 45, 7; 51, 7-8 - o desprecio por la inconstancia de los fieles cristianos son actitudes que pueden atribuirse a la Historia Augusta. En varios momentos puede intuirse también cierta burla en veladas alusiones a autores cristianos. ${ }^{55}$

Uno de los pocos textos en los que se hace mención a los cristianos en la Historia Augusta explica un litigio entre cristianos y taberneros [popinarii] por el uso de un lugar público. Este texto es célebre, entre otras cosas, por contener un extraño hápax que, en cierto modo, dificulta la comprensión de su sentido:

Los cristianos, diciendo que les debía pertenecer, ocuparon cierto lugar previamente público, enfrentándose con ello a los taberneros. Alejandro resolvió el conflicto estableciendo la siguiente norma: Sea como fuere el culto que allí se dé a dios [o Siempre que el espacio sea empleado para rendir culto a dios: ut quemammodumcumque illic deus colatur], debe preferirse a que el lugar se entregue a los taberneros (HA, Alex. Sev. 49, 6)..$^{5}$

El texto parece contener un rescripto imperial que concede el privilegio para el uso de un "locus publicus" a una corporación religiosa frente a las reclamaciones de

54. Birley, 1991, pp. 42-43.

55. Birley, 1991, p. 45 ("personal names inserted to mock Christians"). Rohrbacher, 2016 ha analizado las ironías presentes en las alusiones a autores cristianos como San Jerónimo.

56. Cum Christiani quendam locum, qui publicus fuerat, occupassent, contra popinarii dicerent sibi eum deberi, rescripsit melius esse, ut quemammodumcumque illic deus colatur, quam popinariis dedatur. El hápax quemammodumcumque es traducido por Blánquez, 1985, p. 1288, como "de cualquier manera que sea". 
un gremio mercantil y, por ello, ha sido considerado como una decisión propia de la política religiosa imperial de tolerancia de cultos. ${ }^{57}$

A mi modo de ver del texto se pueden dar otras lecturas. La apropiación cristiana de los espacios públicos de la ciudad de Roma debió desarrollarse a lo largo del s. IV. Debió tratarse de un proceso práctico a la vez que simbólico paralelo al de la cristianización del Estado y la sociedad romana. El ritmo lento y constante de la cristianización de los espacios en la capital adquirió un hito identificable con la labor del papa Dámaso (304-384). Además de impulsar una importante labor edilicia, el papa Dámaso decidió distribuir por la ciudad inscripciones métricas conmemorativas de lugares y hechos relacionados con la implantación del Cristianismo en la Urbe: las catacumbas con los restos de los apóstoles Pedro y Pablo, baptisterios, epitafios de mártires, sepulcros de santos, elogios de obispos... ${ }^{58}$ Esta intervención debió redefinir de modo radical la topografía de la ciudad, así como los usos que de los espacios urbanos pudieron realizar en adelante sus habitantes. Resulta difícil pensar que la potencia del programa epigráfico del papa Dámaso pasara desapercibida a sus contemporáneos, por eso propongo que el gesto de apropiación espacial que hay detrás del mismo pudiera ser objeto de mofa por parte del texto de la Vita Alexandri Severi. En el texto de la Historia Augusta, la apropiación cristiana del lugar se produce en competencia con los popinarii romanos, cuyas aspiraciones se sitúan en el mismo nivel legal y simbólico que las pretensiones de los cristianos. ¿Un nuevo guiño de la Historia Augusta para banalizar cualquier voluntad de trascendencia?

\section{Bibliografía}

Adams, J.N. (1982). The Latin Sexual Vocabulary. Londres: Duckworth.

Adams, G.W. (2013). Marcus Aurelius in the Historia Augusta and Beyond. Lanham et al.: Lexington Books.

Alföldi, A. (1967). Studien zur Geschichte der Wetlkrise des 3. Jahrhunderts nach Christus. Darmstadt: Wissenschaftliche Buchgesellschaft.

Alvar, J. (2001). Los misterios. Religiones “orientales” en el Imperio Romano. Barcelona: Crítica. Ballesteros, J.R. (2006). Histoire et utopie dans les Admiranda de Lipse. De Gulden Passer, 84, pp. 177-191.

57. Alföldi, 1967, pp. 431-435 [= Klio 31, 1938, 249-253].

58. Estas inscripciones han sido objeto de varias eds. He manejado la de Ihm, 1895 que identifica 62 inscripciones damasianas y 45 pseudodamasianas. Con motivo de este proyecto, Filócalo, el calígrafo del papa, desarrolló un tipo de letra capital epigráfica que se haría célebre en el Renacimiento. 
Ballesteros, J.R. (2016). Casaubon en París: La anotación de la Historia Augusta (1603) en la polémica religiosa de tiempos de Enrique IV de Francia. Quaderni di Storia, 84, pp. 83-126.

Ballesteros, J.R. (2018). El jardín y el monstruo: La Historia Augusta y el emperador Adriano en el Humanismo. En Romero, 2018, pp. 97-123.

Bassols de Climent, M. (1964-1970). C. Suetonio Tranquilo: Vida de los doce Césares (texto revisado y trad.), 4 vols. Barcelona : Alma Mater.

Beard, M. (2014). Laughter in Ancient Rome. On Joking, Ticking, and Cracking up. Berkeley, Los Ángeles y Londres: University of California Press.

Bertrand-Dagenbach, C. (2014). À propos des sacrifices d'enfants d'Héliogabale. En Bertrand-Dagenbach y Chausson, 2014, pp. 31-39.

Bertrand-Dagenbach, C. y Chausson, Fr. (eds.) (2014). Historiae Augustae Colloquium Nanceiense. Atti dei Convegni sulla Historia Augusta XII. Bari: Edipuglia.

Birley, A.R. (1991). Religion in the Historia Augusta. En Bonamente y Duval, 1991, pp. 29-51. Binaghi Fasce, J. (1998). Història Augusta (trad. cat.). Barcelona: La Magrana, l’Esparver clàssic.

Bittarello, M.B. (2011). Otho, Elagabalus and the Judgement of Paris: the Literary Construction of the Unmanly Emperor. Dialogues d'Histoire Ancienne, 37.1, pp. 93-113.

Blánquez, A. (1985). Diccionario latino-español español latino, t. 2. Barcelona: Sopena.

Bonamente, G. y Duval, N. (eds.) (1991). Historiae Augustae Colloquium Parisinum. Macerata: Universitá degli studi di Macerata.

Bonamente, G. y Mayer, M. (eds.) (1996). Historiae Augustae Colloquium Barcinonense. Atti dei Convegni sulla Historia Augusta IV. Bari: Edipuglia.

Brashear, W.M. (1995). The Greek Magical Papyri: an Introduction and Survey; Annotated Bibliography (1928-1994). ANRW, II.18.5, pp. 3380-3684.

Calvo Navarro, F. (1919). Escritores de la Historia Augusta, 3 tomos (trad. cast.). Madrid: Librería de la Viuda de Hernando y $C^{a}$.

Cameron, A. (2011). The Last Pagans of Rome. Oxford: Oxford University Press.

Carlozzo, G. (1978). Il faceto nella Historia Augusta. Pan. Studi dell' Istituto di Filologia Latina, 6, pp. 59-64.

Carrington Bolton, H. (1893). A Modern Oracle and Its Prototypes. A Study in Catoptromancy. The Journal of American Foklore, 6.20, pp. 25-37.

Casaubon, I. (1603). In Aelium Spartianum, Iulium Capitolinum, Aelium Lampridium, Vulcatium Gallicanum, Trebellium pollionem et Flavium Vopiscum, emendationes ac notae. París: Ambrosio Drouart.

Cascón, A. (1996). El humor en la Historia Augusta: características literarias y función crítica. En Bonamente y Mayer, 1996, pp. 147-163,

Chastagnol, A. (1994). Histoire Auguste. Les empereurs romains des IIe et IIIe siècles (ed., trad. fr., com.). París: R. Laffont.

Contreras Valverde, J., Ramos Acebes, G. y Rico Rico, I. (1992). Diccionario de la Religión romana. Madrid: Ediciones Clásicas. 
Cortés Copete, J.M. (2006). Claudio Eliano: Historias curiosas (trad., introd. y not.). Madrid: Gredos.

D’Angeli, C. y Paduano, G. (2001). Lo cómico. Madrid: Machado Libros [orig. ital. 1999].

Daniels, S.G. (2013). Satire in the Historia Augusta (A Dissertation presented to the Graduate School of the University of Florida in Partial Fulfilment of the Requirements for the Degree of Doctor of Philosophy 2013) = ufdc.ufl.edu/UFE0045915\%5C00001 [consulta: 21.04.2018].

Delatte, A. (1932). La Catoptromancie grecque et ses dérivés. Lieja y París: Imp. H. VaillantCarmanne.

Delrio, M. (1679). Disquisitionum magicarum libri sex, quibus continentur accurata curiosarum artium et vanarum superstitionum confutatio, utilis Theologicis, Jurisconsultis, Medicis, Philologis. Colonia: Sumptibus Petri Henningij [orig. 1603].

Flint, V., Gordon, R., Luck, G. y Ogden, D. (1999). Witchcraft and Magic in Europe. Ancient Greece and Rome. Londres: Athlone.

Fündling, J. (2006). Kommentar zur vita Hadriani der Historia Augusta, 2 tomos. Bonn: Habelt.

Gil Fernández, L. (1997). La risa y lo cómico en el pesamiento antiguo. Cuadernos de Filología Clásica. Estudios griegos e indoeuropeos, 7, pp. 29-54.

Geffcken, J. (1920). Religionsgeschichtliches in der Historia Augusta. Hermes, 55.3, pp. 279295.

Gordon, R. (1997). Reporting the Marvellous: Private Divination in the Greek Magical Papyri. En Schäfer y Kippenberg, 1997, pp. 65-91.

Gordon, R. (1999). Imagining Greek and Roman Magic. En Flint, Gordon, Luck y Ogden 1999, pp. 161-275.

Hohl, E. (1965). Scriptores Historiae Augustae, 2 vols. Leipzig: Teubner.

Huizinga, J. (1968). Homo ludens. Buenos Aires: Emecé Editores [orig. neerl. 1938].

Ihm, M. (ed.) (1895). Anthologiae Latinae Supplementa. Vol 1. Damasi Epigrammata. Leipzig: Evangelische Verlagsanstalt.

Le Gall, J. y Le Glay, M. (1995). El Imperio romano. El Alto Imperio, desde la batalla de Actium hasta la muerte de Severo Alejandro (31 a.C-235 d.C.). Madrid: Akal.

Lupanus, V. [= Vincent de la Loupe] (1560). Annotationes in Aelium Spartianum, Iulium Capitolinum, Aelium Lampridium, Vulcatium Gallicanum, Trebellium Pollionem, Flavium Vopiscum. París: Andreas Wechel.

Mayer I Olivé, M. (2014). Asinus in tegulis: La pervivencia de un tópico literario a propósito de Hist. Aug., Pert. 1.1-4. En Bertrand-Dagenbach y Chausson, 2014, pp. 335-340.

Motschmann, C. (2002). Die Religionspolitik Marc Aurels. Stuttgart: Franz Steiner Verlag.

O'Gorman, E. (2000). Irony and Misreading in the Annals of Tacitus. Cambridge: Cambridge University Press.

Optendrenk, T. (1969). Die Religionspolitik des Kaisers Elagabal im Spiegel der Historia Augusta. Bonn: Habelt.

Pagán, V.E. (2017). Tacitus. Londres y Nueva York: I. B. Tauris \& Co. 
Paschoud, Fr. (2014). Casaubon et Saumaise commentateurs de l'Histoire Auguste. En Bertrand-Dagenbach y Chausson, 2014, pp. 405-418.

Peucer, G. (1593). Commentarius de praecipuis divinationum generibus [...]. Frankfurt: Ioannes Crato Printer.

Picard, G.C. (1959). Pertinax et les prophètes de Caelestis. Revue de l'histoire des religions, 155.1, pp. 41-62.

Picón, V. y Cascón, A. (1989). Historia Augusta (trad. cast.). Madrid: Akal.

Ratti, St. (2014). Fiction, déconstruction et religion: L'effacement du sens dans l' Histoire Auguste. En Bertrand-Dagenbach y Chausson, 2014, pp. 419-433.

Ratti, St. (2016). L'Histoire Auguste: Les païens et les chrétiens dans l'Antiquité tardive. París: Les Belles Lettres.

Reekmans, T. (1997). Notes on Verbal Humour in the Historia Augusta. Ancient Society, 28, pp. 175-207.

Reekmans, T. (2002). Notes on Non-Verbal Humour in the Historia Augusta. Ancient Society, 32, pp. 315-336.

Rohrbacher, D. (2016). The Play of Allusion in the 'Historia Augusta'. Madison y Londres: University of Wisconsin Press.

Romero, M. (ed.) (2018). El legado de los emperadores hispanos. Sevilla: Universidad de Sevilla.

Schäfer, P. y Kippenberg, H.G. (1997). Envisioning Magic. A Princeton Seminar and Symposium. Leiden, Nueva York y Colonia: Brill.

Shumate, N. (2006). Nation, Empire, Decline. Studies in Rhetorical Continuity from the Romans to the Modern Era. Londres: Duckworth.

Syme, R. (1968). Ammianus and the Historia Augusta. Oxford: Clarendon Press.

Syme, R. (1971). Emperors and Biography. Studies in the Historia Augusta. Oxford: Clarendon Press.

Syme, R. (1983). Historia Augusta Papers. Oxford: Clarendon Press [“Astrology in the Historia Augusta”, orig. 1972/194 (1976)]

Tovar, A. y Belfiore Mártire, M.T. (1984). Propercio: Elegías (ed., trad. cast., introd. y not.). Madrid: Gredos. [1 $1^{\text {a }}$ ed. 1963]

Tuczay, C.A. (2002). Die Kunst der Kristallomantie und ihre Darstellung in deutschen Texten des Mittelalters. Mediaevistik, 15.1, pp. 31-50.

Turcan, R. (1986). Héliogabale précurseur de Constantin?. Bulletin de l'Association Guillaume Budé, 1, pp. 38-52. 